\section{O PAPEL DA MÍDIA NOS SERVIÇOS DE SAÚDE}

É inegável a grande influência da mídia sobre os comportamentos adotados pela sociedade moderna. Com isso, surge a discussão sobre o impacto dos meios de comunicação de massa sobre o sistema de saúde da população. Visando analisar parte dessa relação, alguns trabalhos têm estudado o papel da mídia na dinâmica dos serviços de saúde.

Estudo realizado por Taberner et al. ${ }^{1}$ analisou a procura por atendimento num grande pronto-socorro cardiológico no período subsequente à morte por infarto agudo do miocárdio de um grande personagem da mídia. Foram demonstradas modificações significativas no atendimento naquele período sem, contudo, ter havido aumento no número de internações ou de diagnósticos de infarto. Os autores sugerem que a morte súbita de indivíduos famosos como o humorista Bussunda pode aumentar o número de pacientes que procuram o serviço de emergência cardiológica, assim como alterar o perfil demográfico dos mesmos. Outros trabalhos também têm abordado o tema, demonstrando o alcance populacional da mídia em diversos níveis sociais ${ }^{2}$ e sua influência sobre o sistema de saúde, não só no que se refere à procura por atendimentos de emergência ${ }^{3}$, mas no planejamento de intervenções médicas futuras ${ }^{4}$.

Com o objetivo de observar a reprodutibilidade desses achados, conduzimos um estudo sobre 0 atendimento cardiológico no pronto-socorro do Instituto do Coração (InCor) do HCFMUSP durante o mês de junho de 2008, quando ocorreu o óbito da ex-primeira dama e antropóloga Ruth Cardoso (24 de junho de 2008), o qual obteve grande repercussão na mídia durante um curto espaço de tempo. Foram analisados 3.614 pacientes atendidos nesse período, com o número de atendimentos diários demonstrados no gráfico.

Podemos notar, a partir dos dados desse gráfico, que não houve alterações significativas sobre o perfil de atendimentos realizados durante o período estudado, diferentemente do que foi observado no estudo de Taberner et al. Portanto, apesar da ampla divulgação dos meios de comunicação sobre o óbito repentino de uma conhecida personalidade, não houve, nessa avaliação, alteração do atendimento no maior pronto-socorro cardiológico do Brasil. Algumas hipóteses, no entanto, podem ser formuladas para tentar explicar esses achados.

Primeiramente, para que alguma noticia cause impacto sobre a população é necessário que o público se identifique com a situação e a relacione com sua própria realidade. De fato, os acontecimentos se deram em momentos distintos: enquanto a morte do humorista esteve relacionada à Copa do Mundo de futebol, evento de grande divulgação e alcance de público, a morte da antrópologa ocorreu num período em que a mesma já não tinha tanta exposição por parte da imprensa, já que não era mais a primeira-dama do país.

Outro fato importante é que Ruth Cardoso faleceu aos 77 anos de idade, enquanto Bussunda faleceu aos 43 anos. Tradicionalmente, a morte de indivíduos jovens apresenta um impacto

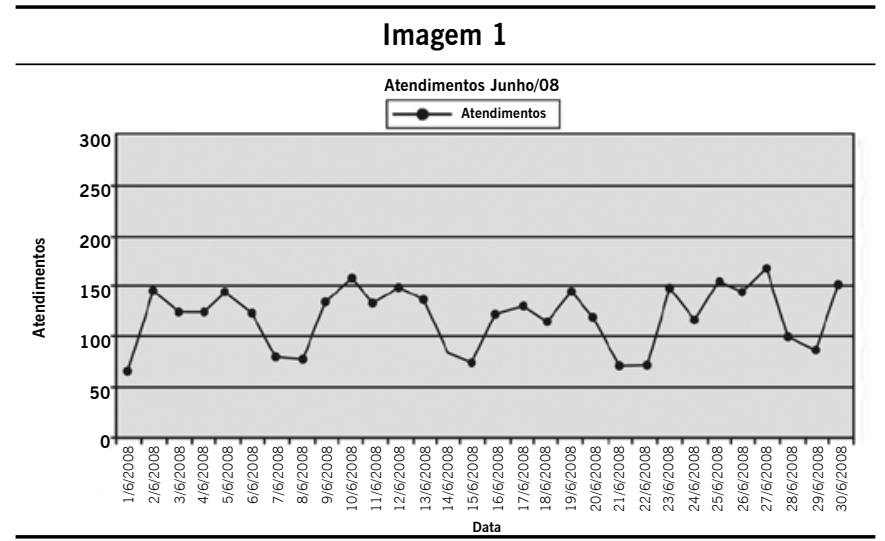

muito maior sobre a sociedade, enquanto a morte de pessoas mais idosas é vista como algo natural e menos traumático. Isso também se refletiu no modo de divulgação dos acontecimentos, que foram bastante distintos. As reportagens sobre a morte de Bussunda focalizaram entrevistas com médicos que alertavam sobre fatores de risco e sintomas do infarto. Já as matérias sobre a morte de Ruth Cardoso destacavam seus feitos e obras ao longo da vida, dando pouca relevância ao evento clínico que culminou em sua morte.

Os meios de comunicação constituem poderosa fonte de influência sobre a sociedade em diversos aspectos, incluindo a utilização dos recursos de saúde. A morte inesperada de uma pessoa pública constitui fato de grande notoriedade e que pode modificar a percepção das pessoas sobre sua saúde. É possível que fatores relacionados às características da personalidade, período do evento e forma de divulgação por parte da mídia tenham influência sobre a demanda populacional pelos serviços de saúde.

Francisco AKIRa André Coelho Marques*

\section{*Correspondência:}

Faculdade de Medicina da Universidade de São Paulo Av. Dr Enéas de Carvalho Aguiar, n44, Andar AB Unidade de Medicina Interdisciplinar em Cardiologia CEP 05403900 - São Paulo - SP

\section{Referências}

1. Taberner JS, Leite PC, Cutait MM, Takada J, Mansur AP, Caramelli B. A influência da mídia nos atendimentos cardiológicos de urgência: O caso Bussunda. Rev Assoc Med Bras. 2007;53(4):335-7.

2. Niederdeppe J, Kuang X, Crock B, Skelton A. Media campaigns to promote smoking cessation among socioeconomically disadvantaged populations: what do we know, what do we need to learn, and what should we do now? Soc Sci Med. 2008;67(9):1343-55.

3. Hodgson C, Lindsay P, Rubini F. Can mass media influence emergency department visits for stroke? Stroke. 2007;38(7):2115-22.

4. Sudore RL, Landefeld CS, Pantilat SZ, Noyes KM, Schillinger D. Reach and impact of a mass media event among vulnerable patients: The Terri Schiavo Story. J Gen Intern Med. 2008;23(11):1854-7.

Errata: Na edição passada, apresentamos erroneamente o título do artigo publicado nesta seção "Correspondência". O título correto é VISUAL OUTCOME OF IDIOPATHIC CENTRAL RETINAL ARTERY OCCLUSION IN A HEALTHY YOUNG PATIENT. 